\title{
Split-Phase Induction Motor Operation from PWM Voltage Source Inverter
}

\author{
K. Gopakumar, V. T. Ranganathan, and S. R. Bhat
}

\begin{abstract}
The operation of split-phase induction motors from pulse width modulated (PWM) voltage source inverters is examined in this paper. Splitting the phase windings leads to reduced voltage ratings for the inverter switches. As compared with seven positions for the space phasor of voltage in three-phase machines, 48 different locations bounded by a 12-sided polygon are possible in the split-phase machine. Based on space phasor modulation, a three-phase inverter can give a maximum peak fundamental of $0.577 V_{D C}$. In comparison, the split-phase configuration can provide an equivalent three-phase maximum peak fundamental of $0.643 V_{D C}$ with a de bus voltage of $0.5 V_{D C} / \cos 15$.
\end{abstract}

\section{INTRODUCTION}

C URRENT source inverter drives using split-phase induction motors are used in industrial applications in order to eliminate sixth harmonic torque pulsations [1]-[3]. The sixth harmonic torque pulsations are produced mainly due to the interaction between the fundamental flux and the fifth and seventh harmonic rotor currents. In the splitphase induction motor configuration, the sixth harmonic torque pulsations produced by the two split-phase groups of coils are in opposition [1]; they get cancelled, and the resultant torque pulsation frequency is 12 times that of the fundamental when fed from a CSI [1]. In this paper, a split-phase motor drive (Fig. 1) with voltage source inverters using voltage space phasor-based PWM technique is examined. The split-phase motor configuration is achieved by splitting the phase belt of a conventional three-phase motor into two equal halves with a phase separation of $30^{\circ}$ between the two (Fig. 2). The splitphase groups, namely $A B C$ and $A^{\prime} B^{\prime} C^{\prime}$ (Fig. 2) are controlled by two inverters with a dc link voltate of $V_{D C} /(2 \cos 15)$ each (Fig 1). Since the split-phase configuration is achieved by splitting the phase belts into two, the equivalent number of turns per phase for the new configuration is $N s / 2 \cos 15(\mathrm{Ns}$ is the equivalent number of turns per phase for the three-phase motor configuration), and correspondingly, a link voltage of $V_{D C} / 2 \cos 15$ gives the same magnitude for the air-gap flux in the new configuration as compared with the three-phase inverter drive with a dc link voltage $V_{D C}$.

For the proposed scheme (Fig. 1), the voltage space phasor locations for the split-phase group of coils, namely $A B C$ and $A^{\prime} B^{\prime} C^{\prime}$ are shown in Fig. 3(a). The voltage space phasor locations for the $A^{\prime} B^{\prime} C^{\prime}$ phase group are phase shifted by $30^{\circ}$

Paper IPCSD 92-38, approved by the Industrial Drives Committee of the IEEE Industry Applications Society for presentation at the 1991 Industry Applications Society Annual Meeting, Dearborn, MI, September 28-October 4. Manuscript released for publication October 19, 1992

The authors are with CEDT, Indian Institute of Science, Bangalore, India. IEEE Log Number 9210099 .

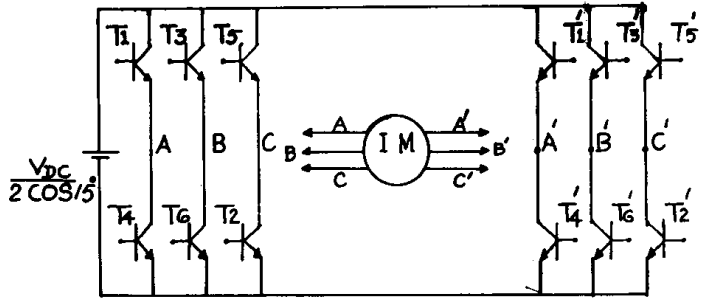

Fig. 1. Split-phase induction motor drive.

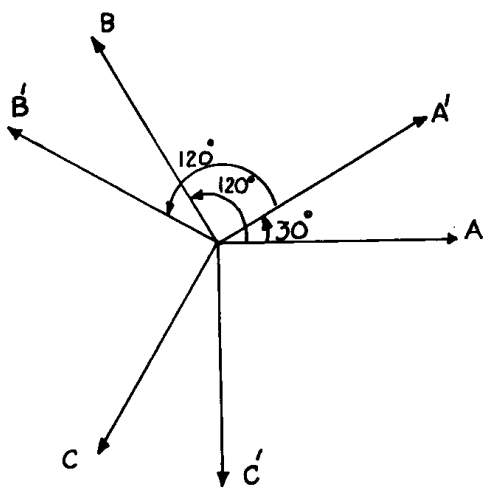

Fig. 2. Phasor diagram-Split phase motor.

from those of the $A B C$ phase group for the same switching state. The sequence $1^{\prime}, 2^{\prime}, 3^{\prime}, 4^{\prime}, 5^{\prime}, 6^{\prime}$ is that of the $A^{\prime} B^{\prime} C^{\prime}$ phases, and the sequence $1,2,3,4,5,6$ is that of the $A B C$ phases (Fig 3(a)) [4], [5]. A switching state of $(+--)$ for the $A B C$ phases implies that the top switch of the $A$ phase and the bottom switches of the $B$ and $C$ phases are on [4], [5]. The sequence of switching states of the inverter for quasi-square-wave operation is shown in Fig. 3(a).

With a three-phase inverter, the boundary of the voltage space phasors is a hexagon (Fig. 3(a)) [4], [5]. With a splitphase configuratiion, by using appropriate switching states for the two inverters, a 12 -sided polygon forms the boundary as shown in Fig. 3(a). Therefore, a given voltage space phasor may be in one of the 12 possible sectors as shown in Fig. 3(a).

By considering different combinations of the switching states for the two inverters, it can be shown that 48 distinct space phasor locations are possible, in addition to the zero space phasor. The 48 space phasors locations and the corresponding switching states of inverters are shown in Fig. 3(b). It can be seen from this figure that the space phasor locations 


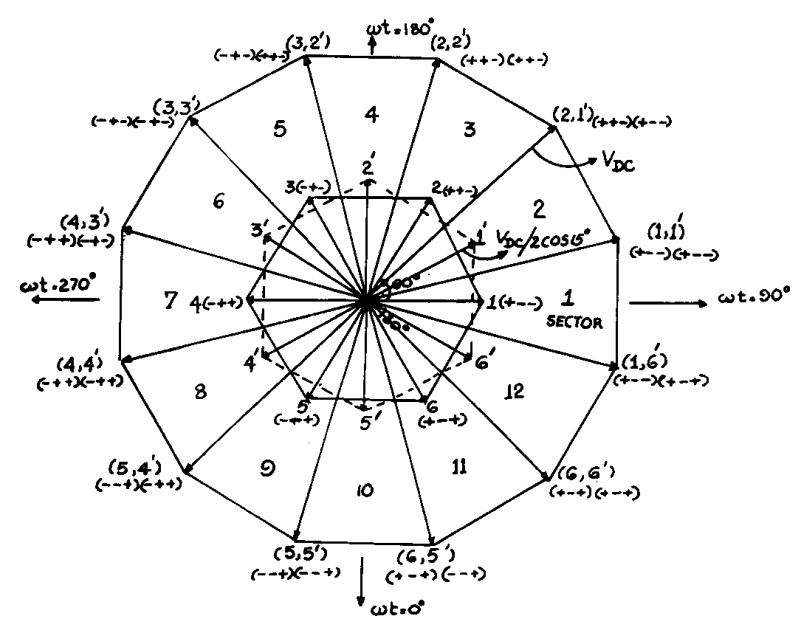

(a)

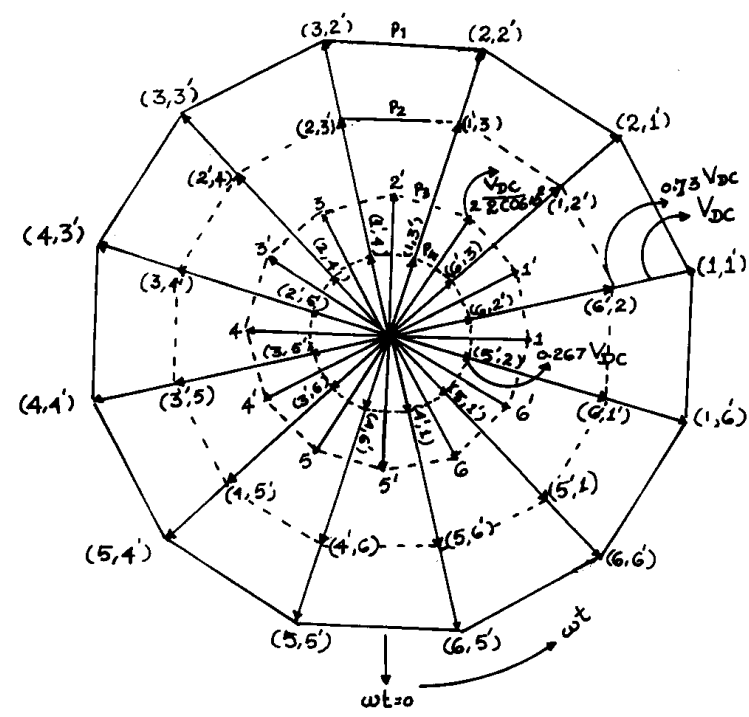

(b)

Fig. 3. (a) Voltage space phasor locations for split-phase induction motor drive. (b) Interior space phasor combinations.

lie at the vertices of four 12-sided polygons $P 1-P 4$. It should be noted that on polygon $P 3$, the vertices correspond to the situation where only one inverter is in a nonzero switching state, and the other is in the zero state. In this paper, PWM generation is discussed with respect to the outermost polygon $P 1$.

\section{Space Phasor PWM Generation FOR SPLIT PHASE INDUCTION MOTOR}

A voltage space phasor rotating with a constant amplitude along a circular trajectory implies sinusoidal excitation for the motor. A circular trajectory can be approximated by switching between any of the appropriate vectors in a sector (Fig. 3) for a three-phase motor [4], [5]. For the split-phase motor configuration, as in the three phase inverter, a rotating reference voltage space phasor is sampled at regular intervals [4], [5]. For example, let the reference vector $\underline{V s}$ be in sector 1

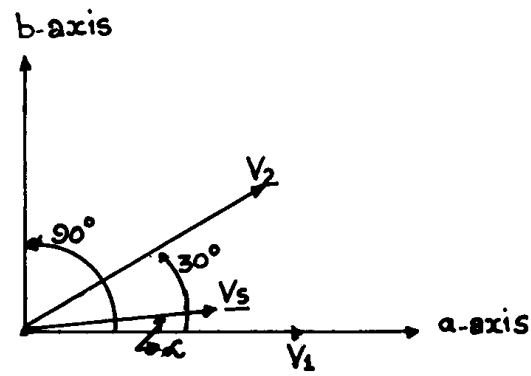

Fig. 4. Sampled reference vector in a sector.

TABLE I

\begin{tabular}{|c|c|c|c|c|c|c|c|c|}
\hline$S$ & & IVERTEP & $2-1$ & & & IVERTE & $R-2$ & \\
\hline ' & 0 & $V_{1}$ & $V_{2}$ & 0 & 0 & $V_{1}$ & $V_{2}$ & 0 \\
\hline 1 & $+t+$ & +-- & $t--$ & --- & +++ & $t-t$ & +-- & --- \\
\hline 2 & --- & +-- & $+t-$ & $+t+$ & --- & +-- & +-- & +++ \\
\hline 3 & --- & ++- & ++- & +++ & $-\cdots$ & +-- & ++- & $+t+$ \\
\hline 4 & $+t+$ & ++- & -+- & --- & +++ & ++- & ++- & -- \\
\hline 5 & +++ & -+- & -+- & --- & +++ & ++- & -+- & -- \\
\hline 6 & --- & -+- & -++ & +++ & --- & $1-+-$ & $-t-$ & +++ \\
\hline 7 & --- & $-t+$ & $-t+$ & $+t+$ & --- & -+- & -++ & +++ \\
\hline 8 & $t+t$ & -++ & --+ & - & $++t$ & -++ & -++ & $-\cdots$ \\
\hline 9 & $+t+$ & --+ & --+ & --- & +++ & -++ & --+ & -- \\
\hline 10 & -- & --+ & +-+ & +++ & -- & --+ & --+ & +++ \\
\hline 11 & -- & +-+ & +-+ & +++ & -- & --+ & $+-t$ & +++ \\
\hline 12 & $++t$ & $t-t$ & +-- & - & $t+t$ & +-+ & +-+ & --- \\
\hline
\end{tabular}

(Fig. 4). Let the state $(+--)(+-+)$ that defines the start of the sector be represented by $V_{1}$ and the state $(+--)(+--)$, which defines the end of the sector, be represented by $V_{2}$. During a sampling interval $T s$, let the reference vector $\underline{V s}$ make an angle $\alpha$ with respect to $V_{1}$ (Fig. 4). The stationary vector $\underline{V s}$ during a sampling interval $T s$ can be generated by switching between $V_{1}, V_{2}$ and the zero vector 0 (Table I) for periods $T 1, T 2$, and $T 0$ such that the volt-seconds produced by the $V_{1}$ and $V_{2}$ states along the axis $a$ and axis $b$ (Fig. 4) will be equal to that of the volt-seconds produced by the $\underline{V s}$ vector along the " $a$ " and " $b$ " axes [3], [4].

The switching states appropriate for all the sectors are shown in Table $\mathrm{I}$. The zero vector period $T 0$ is divided equally between the two zero states $(+++)$ and $(---)$ and is located at the start and end of a sampling period $T s$ [4]. It can be shown that

$$
\begin{aligned}
& T 1=2 K T s \sin (30-\alpha) \\
& T 2=2 K T s \sin \alpha \\
& T 0=T s-(T 1+T 2)
\end{aligned}
$$

where $K=|\underline{V s}| / V_{D C}$ and, Ts is the sampling period. 


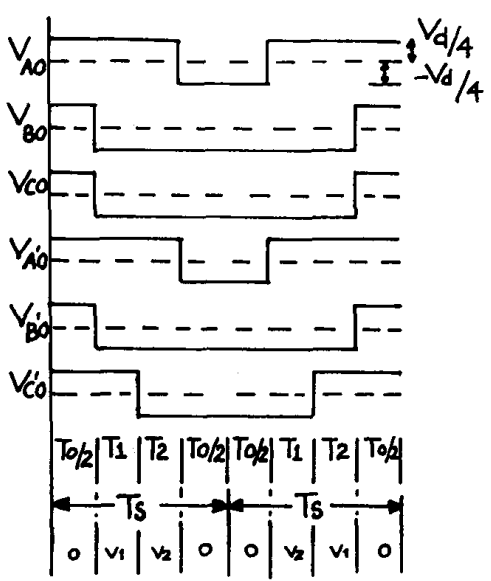

Fig. 5. Pole voltage waveforms for an inverter switching period in sector -1 .

\section{INVERTER POLE VOLTAGE WAVEFORM}

The inverter pole voltage (phase-to-dc center tap) waveforms for an inverter switching period in Sector 1 are shown in Fig. 5. The average value of the pole voltage $V_{A 0}$ in Sector 1 can be determined from (2)

$$
V_{A 0} \text { average }=[T 0 / 2+T 1+T 2-T 0 / 2] * V d / 4 T s
$$

where $V d=V_{D C} / \cos 15$.

Substituting for $T 1, T 2$, and $T 0$ from (1)

$$
V_{A 0} \text { average }=(2 K V d / 4) * 0.5176 * \sin (\alpha+75) .
$$

Similarly, the average variation of the pole voltages for other phases can also be determined

$$
\begin{aligned}
& V_{B 0} \text { average }=-(2 K V d / 4) * 0.5176 * \sin (\alpha+75) \\
& V_{C 0} \text { average }=-(2 K V d / 4) * 0.5176 * \sin (\alpha+75) \\
& V_{A^{\prime} 0} \text { average }=+(2 K V d / 4) * 0.5176 * \sin (\alpha+75) \\
& V_{B^{\prime} 0} \text { average }=-(2 K V d / 4) * 0.5176 * \sin (\alpha+75) \\
& V_{C^{\prime} 0} \text { average }=-(2 K V d / 4) * 1.932 * \sin (\alpha-15) .
\end{aligned}
$$

By considering the average pole voltage variation in the other sectors, the average pole voltage variations for a cycle can be computed and is shown in Fig. 6 for the maximum reference space phasor with a circular trajectory. This method of PWM can therefore be regarded as equivalent to a carrierbased modulation technique where the reference waveform has the shape shown in Fig. 6. For a maximum reference space phasor with a circular trajectory, the value of $K$ is $|\underline{V s}| / V_{D C}=\cos 15=0.9659$. For lower values of $K$, the waveform is preserved except for the corresponding reduction in amplitude.

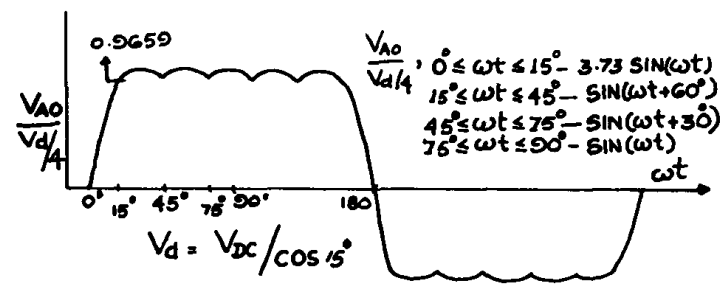

Fig. 6. Average pole voltage variation.

IV. HARMONIC ANALYSIS OF THE AVERAGe Pole Voltage WaVeform

The harmonic analysis of the pole voltage waveform for the maximum reference space phasor with a circular trajectory can be obtained from Fig. 6 . The equation for the fundamental component is given by

$$
\begin{aligned}
A 1= & (V d / 4)(4 / \pi)\left[\int_{0}^{15^{\circ}} 3.732 \sin ^{2} w t d(w t)\right. \\
& +\int_{15^{\circ}}^{45^{\circ}} \sin (w t+60) \cdot \sin w t d(w t) \\
& +\int_{45^{\circ}}^{75^{\circ}} \sin (w t+30) \sin w t d(w t) \\
& \left.+\int_{75^{\circ}}^{90^{\circ}} \sin w t(d w t)\right]=0.3109 V d
\end{aligned}
$$

where

$$
V d=V_{D C} / \cos 15
$$

If the fundamental components of the 12-pole voltages are transformed to two orthogonal axes, the resultant voltage space phasor for the fundamental component can be obtained. Assuming one axis along the $A$-phase coil, the resultant along that axis is given by [1]

$$
\begin{array}{rl}
V d & * 0.3109[\cos w t-(1 / 2) \cos (w t-120) \\
& -(1 / 2) \cos (w t+120)+(\sqrt{3} / 2) \cos (w t-30) \\
& -(\sqrt{3} / 2) \cos (w t-150)]=0.933 V d \cos w t .
\end{array}
$$

Now, substituting for $V d$, the fundamental component for the line-to-neutral voltage for an equivalent three-phase system can be calculated and is given by [4], [5]

$$
(2 / 3) 0.933 V d \cos w t=0.643 V_{D C} \cos w t .
$$

The other higher order harmonics of the average pole voltage waveform can be determined from (13)

$$
\begin{aligned}
A n= & 3.732 \frac{V d}{\pi}\left[-\frac{\sin (n+1) \pi / 12}{2(n+1)}+\frac{\sin (n-1) \pi / 12}{2(n-1)}\right] \\
& +\frac{V d}{\pi}\left[\frac{\sin \left((n+1) \frac{\pi}{12}+60\right)}{2(n+1)}-\frac{\sin \left((n+1) \frac{\pi}{4}+60\right)}{2(n+1)}\right. \\
& \left.+\frac{\sin \left((n-1) \frac{\pi}{4}-60\right)}{2(n-1)}-\frac{\sin \left((n-1) \frac{\pi}{12}-60\right)}{2(n-1)}\right] \\
& +\frac{V d}{\pi}\left[\frac{\sin \left((n+1) \frac{\pi}{4}+30\right)}{2(n+1)}-\frac{\sin \left((n+1) 5 \frac{\pi}{12}+30\right)}{2(n+1)}\right.
\end{aligned}
$$


TABLE II

Order of Harmonics Present in the Average Pole Voltage Waveform

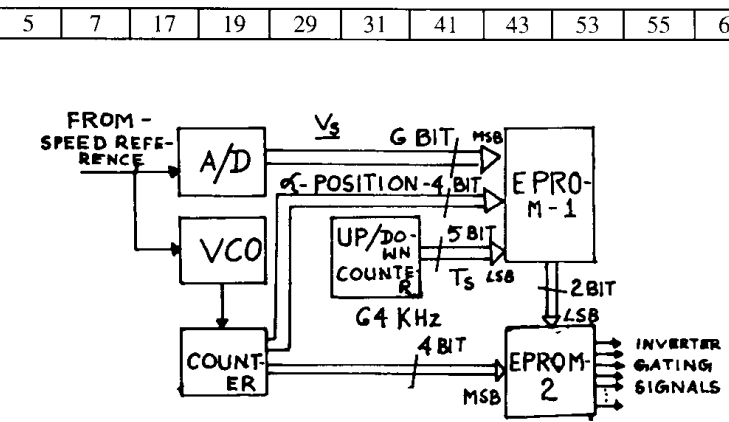

Fig. 7. PWM pattern generation.

$$
\begin{aligned}
& +\frac{\sin \left((n-1) 5 \frac{\pi}{12}-30\right)}{2(n-1)}-\frac{\sin \left((n-1) \frac{\pi}{4}-30\right)}{2(n-1)} \\
& +\frac{V d}{\pi}\left[\frac{\sin (n+1) 5 \frac{\pi}{12}}{2(n+1)}-\frac{\sin (n+1) \frac{\pi}{2}}{2(n+1)}\right. \\
& \left.+\frac{\sin (n-1) \frac{\pi}{2}}{2(n-1)}-\frac{\sin (n-1) 5 \frac{\pi}{12}}{2(n-1)}\right] .
\end{aligned}
$$

From (13), the higher order harmonics can be determined, and the order of the harmonics present are shown in Table II From Table II, it can be seen that the harmonics of the order 11, $13,23,25,35,37$, etc. are absent in the average pole voltage waveform. Therefore, the only harmonics that will be present in the motor phase voltages will be of the order five, seven, 17, $19,29,31$, etc. The absence of the first group $(11,13$, etc.) of harmonics means that torque pulsations of order 12,24 , 36 , etc. will be absent. The winding disposition ensures that torque pulsations of order six, 18,30 , etc. will also be absent [1], [3]. Thus, with the proposed scheme, all low-order torque pulsations are eliminated. Further, the proposed scheme offers an equivalent three-phase fundamental line-to-neutral voltage of $0.643 V_{D C}$ (see (12)), which is greater than that for threephase quasisquare-wave operation $\left(0.637 V_{D C}\right)$ while it is still in modulation.

\section{The PWM Pattern Generation}

The simple $V / f$ control scheme is used for the motor drive. The reference signal for $\underline{V s}$ and the inverter output frequency is derived from the speed reference signal. The amplitude of voltage space phasor $\underline{V s}$ is quantized into 64 states by using the lower 6-b output of an A/D converter. In each sector, the $\alpha$ positions are divided into 16 parts by using the lower $4-b$ of an 8-b counter, where the upper 4-b are used for the sector information. A 5-b up down counter working at $64 \mathrm{KHz}$ is used to divide a sampling interval into 32 parts. These 15 -b are used for addressing a 32-Kb EPROM in which the interval for $T 1, T 2$, and $T 0$ are stored. The 15-b address for the EPROM is as shown in Fig. 7.

The values of $T 0, T 1$, and $T 2$ are computed for different $\alpha$ positions in a sector for different $\underline{V s}$ amplitudes, and a stream of bit pattern " 00 " (for the first $T 0 / 2$ period), " 01 " (for the $T 1$ period), "10" (for the $T 2$ period), and " 11 " (for the last $T 0 / 2$

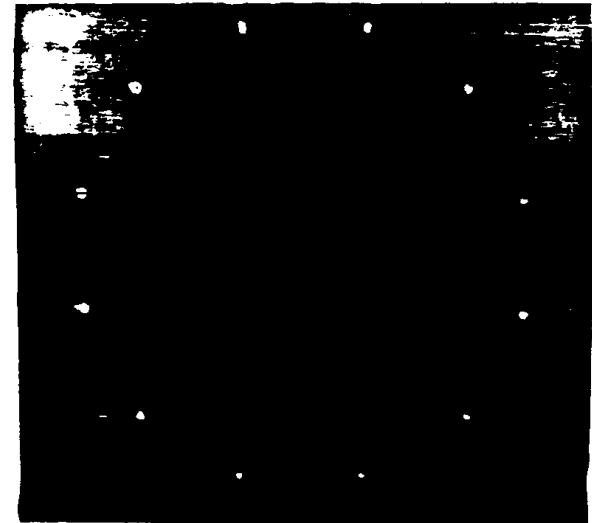

Fig. 8. Twelve-sided polygon for the voltage space phasor, split phase motor

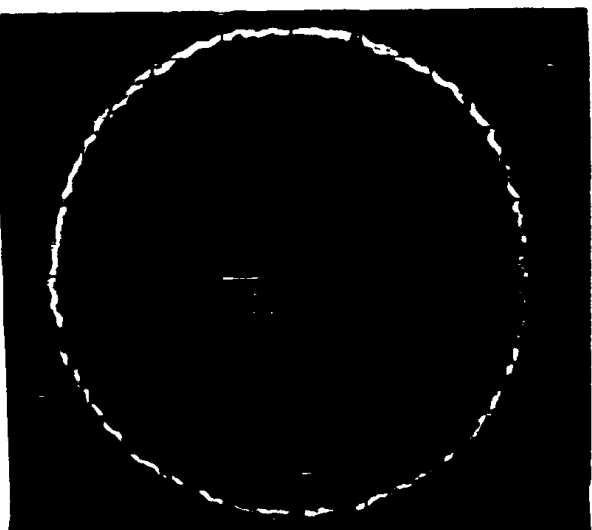

Fig. 9. Circular trajectory of the average reference space phasor voltage.

period) (Table I) are stored in the first EPROM for different values of $|\underline{V s}|$ and $\alpha$. The 2-b pattern from the first EPROM and the higher $4-b$ of the $8-b$ counter for sector information are used for addressing a second EPROM in which switching patterns for various sectors are stored. The output of the second EPROM is used to drive a transistorized inverter for which the inverter switching frequency is $1 \mathrm{KHz}$.

\section{EXPERIMENTAL RESULTS}

A 2.5-Kw split-phase induction motor is tested with a dual voltage source inverter (Fig. 1) using a space phasor-based PWM technique. The 12-sided polygon with its 12 vectors, which is derived from the control signals, are shown in Fig. 8 and the resultant circular trajectory for the reference space phasor is shown in Fig. 9. The motor phase current and its harmonic spectrum are shown in Fig. 10 for no-load operation. The motor operates at $1200 \mathrm{r} / \mathrm{min}$, where the fundamental frequency of the inverter is approximately $21 \mathrm{~Hz}$. The harmonic spectrum shows the fundamental component along with the fifth and seventh harmonic with reduced higher order harmonics. Since the motor runs at no load, the fundamental 

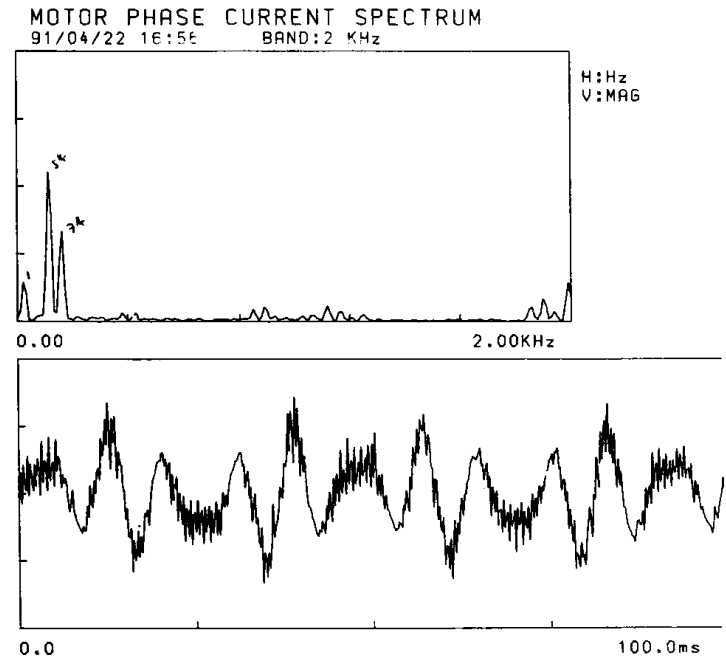

Fig. 10. Motor phase current and its harmonic spectrum.

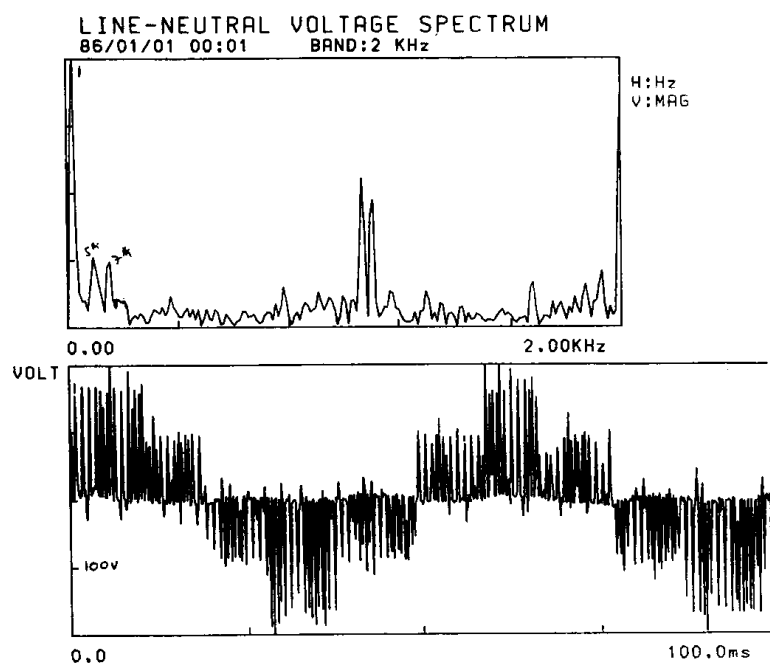

Fig. 11. Line-to-neutral voltage waveform and its harmonic spectrum.

component is only the magnetizing component. Due to the split-phase configuration [1], [3], [4], the fifth and seventh component will not produce any air-gap flux; the impedance for these harmonics is due to the stator impedance only. Hence, the amplitude for these components is higher as compared with the fundamental at no-load operation (Fig. 10). Fig. 11 shows the line-to-neutral waveform and its harmonic spectrum. Figs. 12 and 13 show the line-to-neutral voltage waveform of $A$ phase and $A^{\prime}$ phase and the line-to-line voltage waveform of the $A B$ and $A^{\prime} B^{\prime}$ phases, respectively. The motor line-toneutral waveform and the phase current waveform show that all the harmonic components of the order 11, 13, 23, 25, 35, 37 , etc. are absent in the current waveform and the harmonics of the order five, seven, 17,19 , etc. will contribute nothing to the air-gap flux. Hence, the torque produced will be due to the fundamental component only.

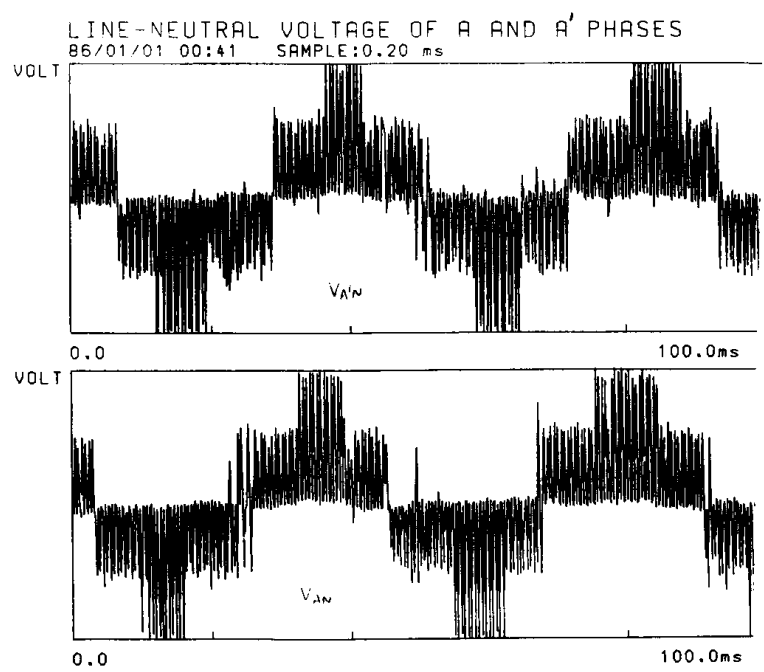

Fig. 12. Line-to-neutral voltage phase $A$ and $A^{\prime}$.

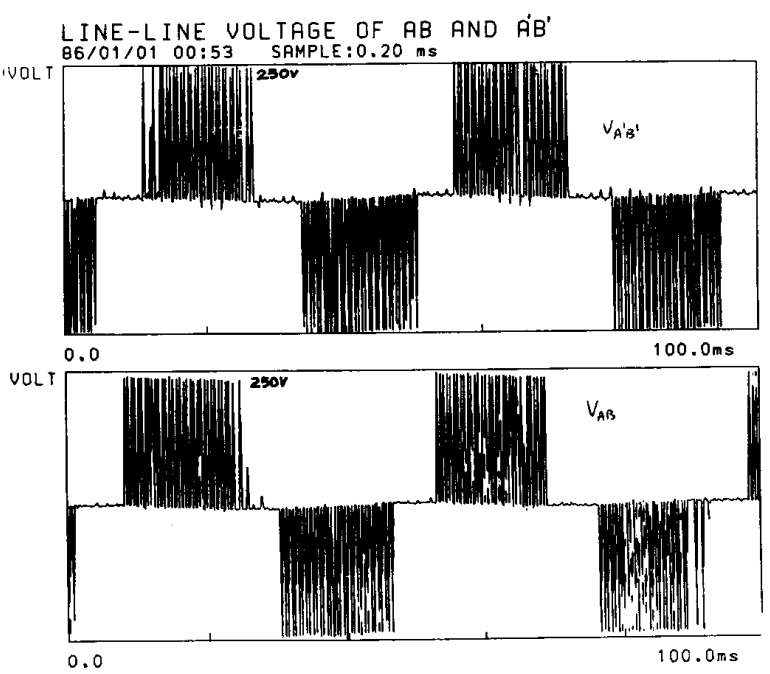

Fig. 13. Line-to-line voltage phase $A B$ and $A^{\prime} B^{\prime}$

\section{CONCLUSION}

Operation of split-phase induction motors from pulse width modulated voltage source inverters has been examined. The salient conclusions that emerged from the study are the following:

1) There are 48 possible locations for the resultant voltage space vector as compared with eight in the conventional three-phase configuration.

2) The boundary of the voltage space phasor locations is a 12-sided polygon as compared witih a hexagon for the three-phase system.

3) The radius of the largest circular trajectory for the voltage space phasor is $V_{D C} * \cos 15=0.9659 V_{D C}$ as compared with $V_{D C} * \cos 30=0.866 V_{D C}$ for the three-phase system. In terms of the fundamental line-to- 
neutral voltage of the equivalent three-phase machine, this tranlates to $0.643 V_{D C}$ for the split-phase arrangement as compared with $0.577 V_{D C}$ for the three-phase configuration.

4) The average inverter pole voltage waveform contains fifth and seventh harmonic components. These harmonic components do not contribute to the resultant air gap flux because the corresponding stator MMF's get cancelled due to the winding disposition.

5) Reference vectors of smaller amplitudes (for lower speed operations) can be generated with reduced switching harmonic contents by switching between the vertices of the inner polygons. The polygon that is closest to the desired trajectory should be selected to give the lowest harmonic content.

\section{ACKNOWLEDGMENT}

During this work, $\mathrm{K}$. Varghese and L. Umanand of CEDT have helped in the control circuitry implementation. Their assistance is gratefully acknowledged. In the fabrication of the power circuit, the assistance rendered by A. P. Saravanan and T. Annathurai is also greatly appreciated.

\section{REFERENCES}

[1] K. Gopakumar et al., "Modified current source inverter fed induction motor drive with reduced torque pulsation," in Proc. Inst. Elec. Eng., vol. 131 , pt. B, no. 4 , July 1984 .

[2] T. A. Lipo, "Design and control techniques for extending high frequency operation of a CSI induction motor drive," in Conf. Rec. IAS Ann. Mtg. 1982, pp. 698-705.

[3] E. Andresen et al., "6-phase induction motors for current source inverter drives," Conf. Rec. IAS Ann. Mtg., 1981, pp. 607-618.

[4] H. W. Van der Broek et al., "Analysis and realisation of a pulse width modulator based on voltage space phasor," IEEE Trans. Ind. Applicat. vol. 24 , no. 1, pp. 142-150, Jan./Feb. 1988

[5] H. Holtz et al., "High speed drive system with ultrasonic MOSFE' PWN inverter and single-chip microprocessor control," IEEE Trans. Ind Applicat., vol. IA-23, no. 6, pp. 1010-1015, Nov./Dec. 1987.

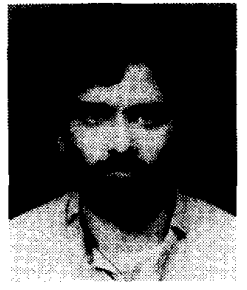

K. Gopakumar received the B.E. and M.Sc. (Engg.) degrees from the Indian Institute of Science in 1980 and 1984 , respectively.

From 1984 to 1987 , he was with the Indian space research organization. In 1987, he joined the Centre for Electronics Design and Technology (CEDT), Indian Institute of Science, as a Scientific Officer. His fields of interest are in power conversion and ac drives.

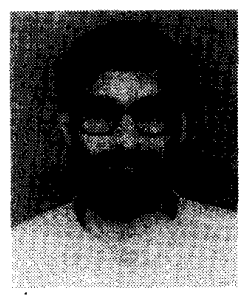

S. R. Bhat received the B.E. degree in electronic engineering from Bangalore University in 1972 and the M.Tech. degree from the Indian Institute of Technology, Kanpur, in 1974. He received the Ph.D. degree from the Indian Institute of Science (IISc) in 1986.

In 1974 , he joined the Centre for Electronics Design and Technology (CEDT), Indian Institute of Science, as a Scientific Officer. He has worked in the areas of linear and digital electronics. From 1982 to the present, he has been working in the area of power electronics. His research and development interests include switchingmode power supplies, induction motor drives, photovoltaic pumping systems, and power-generating systems. He is currently an Assisstant Professor at CEDT, IISc. He has authored several papers and books related to electronics design and technology.

Dr. Bhat is a Fellow of the Institution of Electronics and Telecommunication Engineers (IETE), India.

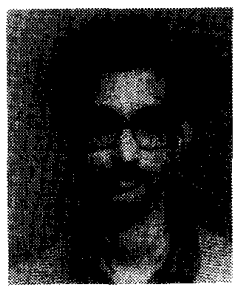

V. T. Ranganathan received the B.E. and M.E degrees from the Indian Institute of Science in 1977 and 1979, respectively, and the Ph.D. degree from Concordia University, Montreal, Canada, in 1983.

Since 1984, he has been a faculty member in the Department of Electrical Engineering, Indian Institute of Science, where he is currently an Associate Professor. His research interests are in the areas of power electronics and drives. He has also acted as consultant to industry in the area of inverters, ups systems, and vector control of ac motors.

Dr. Ranganathan has been the recipient of the Prize Paper Award of the Static Power Converter Committee of the IAS and holds a patent in the area of resonant converters. 